Goldschmidt 2021 Abstract

https://doi.org/10.7185/gold2021.7334

\section{World Map of Orogens: temporal and spatial evolution of orogenic belts (IGCP 667 project)}

\author{
CAMILLE FRANÇOIS ${ }^{1}$, MANUEL PUBELLIER ${ }^{2}$, \\ CHRISTIAN ROBERT ${ }^{3}$, ROMAIN BOUSQUET ${ }^{4}$, SITI NUR \\ FATHIYAH JAMALUDIN ${ }^{5}$ AND IGCP 667 TEAM $^{1}$
}

${ }^{1}$ Commission for the Geological Map of the World

${ }^{2}$ CNRS-ENS Paris-CGMW

${ }^{3}$ ENS Paris

${ }^{4}$ University of Kiel

${ }^{5}$ Universiti Teknologi Petronas

Presenting Author: c.francois.geology@orange.fr

Orogens form in convergence settings involving two or more continental and/or oceanic plates. They are traditionally defined as zones of crustal deformation associated with mountain building resulting from either the accretion of an arc, a continentcontinent collision or the inversion of a rift basin. However, this somewhat narrow definition does not consider for example the genetic link between an oceanic domain and an intra-continental rift, even though extension associated with a scissor-shape opening can be demonstrated in many ocean-floored basins. Consequently, we propose a new concept of orogenic evolution based on the development of extensional margins subsequently subjected to crustal shortening. Thus orogens that develop as a result of the closure of wide basins, and involve the shortening of supra-subduction basins and arcs, are distinguished from mountain belts developed above subduction zones or that result from continental collision. Inverted intra-continental rifts (devoid of oceanic material) are also considered. Our review of illustrative key orogens identifies apparent similarities and differences in geodynamic processes through geological time and emphasizes the lateral spatial and temporal changes that may occur from a subduction to a collisional setting, with such changes being intrinsic to the transition from intra-continental rifts to large basins floored by oceanic crust. We also review the geodynamic processes that operated prior to the onset of plate tectonics. As we go back in time, key tectonic attributes are apparently lost in many cases (but tellingly not all) due to a lack of data, a lack of understanding, or the deeper levels of erosion generally associated with older orogens.

We propose that mapping utilizing tools based on comparative tectonics to understand old terrains and fault zones is a good way to constrain such an evolution and that this can start with a global-scale map of past-to-modern orogens, aimed at reexploring mountain building concepts spatially and temporarily. This is the primary objective of IGCP 667 project "World Map of Orogens".

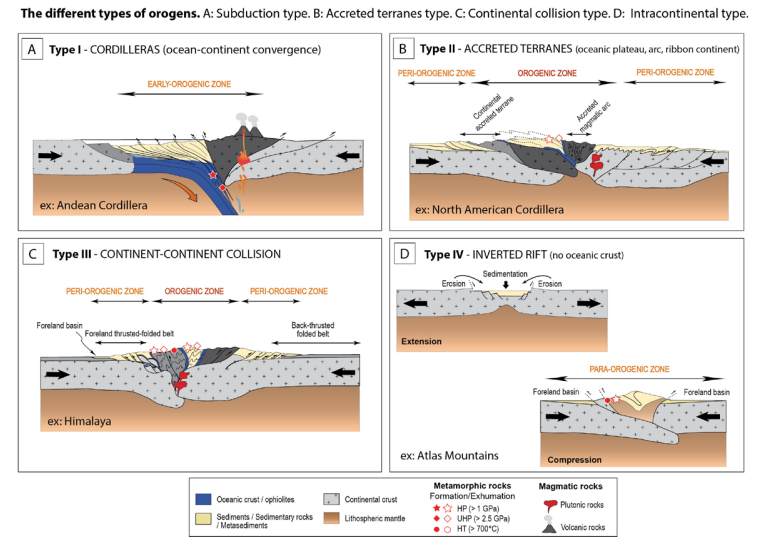

